\title{
Impact of an Advanced Practice Pharmacist Type 2 Diabetes Management Program: A Pilot Study
}

Jelena Lewis, PharmD, BCACP, APh ${ }^{1}$; Tiffany Nguyen, PharmD ${ }^{1}$; Hana Althobaiti, PharmD ${ }^{1}$; Mona Y. Alsheikh PharmD, MSc, PhD ${ }^{2}$;

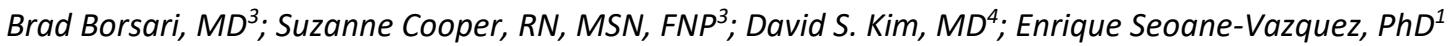

${ }^{1}$ Chapman University School of Pharmacy; ${ }^{2}$ College of Pharmacy, Taif University, Saudi Arabia; ${ }^{3}$ Providence St. Joseph Health System;

${ }^{4}$ Providence St. Joseph Health Physician Enterprise

\begin{abstract}
Background: The purpose of this study was to describe the impact of an Advanced Practice Pharmacist (APh) on lowering hemoglobin A1c $(\mathrm{HbA1c})$ in patients with type 2 diabetes within a patient centered medical home (PCMH) and to classify the types of therapeutic decisions made by the APh.

Methods: This was a retrospective study using data from electronic health records. The study evaluated a partnership between Chapman University School of Pharmacy and Providence St. Joseph Heritage Healthcare that provided diabetes management by an Advanced Practice Pharmacist in a PCMH under a collaborative practice agreement. Change in the HbA1c was the primary endpoint assessed in this study. The type of therapeutic decisions made by the APh were also evaluated. Descriptive analysis and Wilcoxon signed rank test were used to analyze data.

Results: The study included 35 patients with diagnosis of type 2 diabetes mellitus managed by an APh from May 2017 to December 2017. Most of the patients were $60-79$ years old (68.5\%), $45.7 \%$ were female, and $45.7 \%$ were of Hispanic/Latino ethnicity. The average $\mathrm{HbA1C}$ was $8.8 \% \pm 1.4 \%$ (range=6.0\%-12.4\%) and $7.5 \% \pm 1.4 \%$ (range=5.5\%-12.4\%) at the initial and final APh visit, respectively ( $p<0.0001)$. Therapeutic decisions made by the APh included drug dose increase (35.5\% of visits), drug added (16.4\%), drug dose decrease (6.4\%), drug switch (5.5\%), and drug discontinuation (1.8\%).

Conclusion: The Advanced Practice Pharmacist's interventions had a significant positive impact on lowering HbA1c in patients with type 2 diabetes mellitus in a PCMH. The most common therapeutic decisions made by the APh included drug dose increase and adding a new drug.
\end{abstract}

Keywords: accountable care organization, collaborative practice agreement, diabetes, patient centered medical home, therapeutic decisions, advanced practice pharmacist

\section{Background}

According to the Centers for Disease Control (CDC), as of 2015, 30.3 million people representing $9.4 \%$ of the US population have diabetes. ${ }^{1}$ Uncontrolled diabetes can lead to serious complications including an increased risk of cardiovascular disease such as heart attack and stroke. The optimization of patient care is imperative to prevent disease progression and the development of complications. Through collaborative practice agreements (CPAs), the clinical pharmacist can optimize care by providing chronic disease management and independently perform therapeutic interventions to improve quality of care and patient outcomes.

Clinical pharmacists also play an important role in the patient centered medical home (PCMH). $\mathrm{PCMH}$ is a primary care delivery system with emphasis on multi-disciplinary teambased care and inter-professional collaboration among healthcare providers. ${ }^{2-3}$ The $\mathrm{PCMH}$ care model aims to improve

Corresponding author: Jelena Lewis, PharmD, BCACP, APh

Department of Pharmacy Practice

Chapman University School of Pharmacy

9401 Jeronimo Rd, Irvine, CA 92618

Email: jelewis@chapman.edu the patient care experience and control cost through the provision of safe, high quality, evidence-based medicine. ${ }^{3}$ Physicians have an average panel of about 2500 patients. ${ }^{4}$ As a result, physicians may not have enough time during a patient visit to manage chronic illnesses, diagnose acute illnesses, and maintain a positive relationship with their patients. ${ }^{4}$ Comanagement of patient panels by physicians, nurses, pharmacists and other PCMH team members allows for the expansion of primary care services and improvement in quality performance metrics. $^{3}$

Previous studies have looked at providers' perception of pharmacy services in PCMH and how a pharmacist-physician collaboration for diabetes care can impact patient disease management. ${ }^{5-9}$ Providers consider pharmacists to be valuable and integral members of the health care team because the pharmacist can assist in patient management and improve quality as well as performance metrics. ${ }^{3,10-11}$ Other studies have evaluated the impact of pharmacist's involvement on adherence in a team based model and how pharmacist's involvement can lead to reducing drug and overall health care costs. $^{12}$ Many studies concluded that a pharmacist's involvement positively affects diabetes management and could reduce cost. ${ }^{12-24}$ 
In the state of California, pharmacists can hold the special designation of Advanced Practice Pharmacist (APh) if they satisfy certain criteria. The APh is authorized to perform patient assessments, refer patients to other health care providers and initiate, adjust, and discontinue drug therapy. The APh works upon referral from a patient's treating provider and under a protocol. In addition, in collaboration with patient's primary care physician (PCP), the APh can order and interpret drug therapy-related tests and participate in evaluation and management of patient's health conditions. There are limited number of studies that describe the impact of Advanced Practice Pharmacists who practice as mid-level providers in a PCMH and who make decisions and medication adjustments independently under a CPA.

The objectives of this study were to assess the impact of an APh working in a PCMH on reduction in the HbA1c values for patients with type 2 diabetes and to classify the types of therapeutic decisions made by the APh.

\section{Setting}

Providence St. Joseph Heritage Healthcare was founded in 1994. It consists of 8 medical groups and supports six affiliated physician networks in California. There are approximately 175 clinics, 915 medical group providers and 1,327 affiliate providers within Heritage. In May 2017, the administration at Providence St. Joseph Heritage Healthcare was interested in piloting a pharmacist-run, protocol-driven, disease state management (DSM) program at one of its clinics in Southern California, St. Jude Heritage Medical Group (SJHMG). At the time, this PCMH clinic consisted of 6 primary care providers (PCPs), one nurse practitioner (NP), one registered nurse (RN), and a case manager. The aim of the DSM program was to improve chronic care quality metrics, provide better access to care for patients and evaluate the impact of clinical pharmacy services on measures such as $\mathrm{HbA1c}$.

Although our study was a pilot study with only one APh pharmacist, currently, there are seven pharmacists practicing in PCMH clinics consisting of a team of 5-7 PCPs or family medicine physicians, and other health care providers. The team provides collaborative interdisciplinary care for patients. Most recently, a behavioral health provider was also added to the team in some clinics. The clinical pharmacists spend between 1 and 4 days per week at the clinical practice site and attend daily multidisciplinary huddles.

The clinical pharmacists are credentialed by the PCMH at Heritage. Due to the fast expansion of the pharmacy program in the last year, not all the pharmacists have a California Advanced Practice Pharmacist license; however, they plan to apply for this license in the immediate future. The clinical pharmacists work with physicians who are part of the PCMH under a CPA that includes management of type 2 diabetes, hypertension and dyslipidemia. The CPA excludes patients with type 1 and gestational diabetes.
Physicians refer patients to the pharmacists who do not meet the American Diabetes Association (ADA) glycemic goal, as well as patients needing education about medications or lifestyle modification counselling. After obtaining the referral, the clinical pharmacist can independently initiate, modify and discontinue drug therapy; evaluate drug adherence; order and review lab values and vital signs; and recommend lifestyle modifications as needed. The office staff schedules the patients' visits with the pharmacist and each pharmacist has her own schedule. Initial in-office pharmacist visits are scheduled for 1 hour and follow up in-office visits are scheduled for 30 minutes. The clinical pharmacists also manage patients via electronic patient portal or telephonically.

\section{Methods}

This was a retrospective study using electronic health records data. The study was conducted under a partnership between Chapman University School of Pharmacy and Providence St. Joseph Heritage Healthcare System. During the study period, one APh from Chapman University School of Pharmacy spent 12 days per week in a PCMH clinic at Jude Heritage Medical Group and provided diabetes management under a CPA. The change in $\mathrm{HbA1C}$ pre and post $\mathrm{APh}$ management was the primary endpoint assessed in this study. APh was requested to show the value of the interventions within 6 months of starting the program. Thus, the change in $\mathrm{HbA} 1 \mathrm{c}$ was considered an appropriate measure for detecting the effect of the interventions in the relatively short period of analysis. The study included patients diagnosed with diabetes mellitus type 2 and referred to the clinical pharmacist regardless of $\mathrm{HbA1C}$ levels. Patients with type 1 and gestational diabetes were excluded from the study. A chart review was performed of each patient's medical record. The data collected included patient demographics, number of APh visits, type of visit, and the $\mathrm{HbA1c}$ value at the first and successive APh visits. Information was also collected about APh's interventions including adding a new drug, increasing or decreasing the dose of existing drugs, switching to a different drug, and discontinuing a drug. With the help of the Accountable Care Organization (ACO) partner, Blue Shield, and the administration at Heritage Healthcare, the APh pharmacist selected these types of interventions in order to best show the impact of APh presence within the PCMH model.

Data collected were stored in password protected Microsoft Excel file, de-identified and saved in a secure computer. Microsoft Excel and IBM SPSS Statistics 25 software programs were used to analyze the data. Descriptive analysis and Wilcoxon signed rank test were used for the analysis. The effect size and post-hoc power analyses were performed using G*Power. Both Providence St. Joseph Heritage Healthcare and Chapman University IRB approvals were obtained prior to study initiation.

\section{Results}

The study included 35 patients who received comprehensive drug therapy management services for type 2 diabetes mellitus 
by an APh in a St. Jude Heritage PCMH from May 2017 to December 2017. Patients' ages ranged from 30-95 years, with $68.5 \%$ of patients between $60-79$ years old. Female patients represented $45.7 \%$ of the patients and $45.7 \%$ of the patients were of Hispanic/Latino ethnicity (Table 1).

The APh provided 110 visits; with an average \pm standard deviation of $3.1 \pm 1.3$ visits per patient (range 2-6 visits). Visits were conducted in-person (84.5\%), over the phone $(11.8 \%)$ or via a patient portal of the electronic medical record (3.6\%). The average interval between each visit for patients was 100.4 \pm 53.6 days (median 84.0 days).

The APh performed 72 therapeutic interventions with an average of $2.1 \pm 1.4$ interventions per patient (range $0-5$ ) and $0.7 \pm 0.4$ interventions per visit. The therapeutic interventions performed by the APh included dose increase (35.5\% of visits), drug added to the patient's regimen (16.4\%), drug switch (5.5\%), dose decrease (6.4\%), and drug discontinuation (1.8\%) (Table 2). The most common drugs involved in the APh therapeutic interventions were glimepiride (11.8\%), glipizide (5.5\%), insulin glargine (10.9\%), and metformin (19.1\%).

The percentage of patients with a $\mathrm{HbA} 1 \mathrm{c}$ value of $>10.0 \%$ was $14.3 \%$ and $2.8 \%$ pre and post intervention by the APh, respectively. The percentage of patients with elevated HbA1c values decreased, while the percentage of patients with lower $\mathrm{HbA1c}$ values increased pre and post intervention by the APh. (Table 3) The average \pm standard deviation $\mathrm{HbA1c}$ changed from $8.8 \% \pm 1.4 \%$ at baseline to $7.5 \% \pm 1.4 \%$ at the last visit $(Z=-$ $4.408, p<0.001)$. The effect size was large $(d=0.93)$, indicating that the pre-post $\mathrm{HbA} 1 \mathrm{c}$ difference was important. In addition, the result of post-hoc power analysis was large (1-beta=0.9994). Thus, we might assume that the intervention by APh caused a significant reduction in HbA1c. Changes in $\mathrm{HbA1c}$ values varied by patient (Table 4). There were 24 (68.6\%) patients that experienced an HbA1c reduction, 18 (51.4\%) patients that had an absolute $\mathrm{HbA1c}$ reduction of at least $1.0 \%$ and 15 (42.9\%) patients that achieved an $\mathrm{HbA} 1 \mathrm{c}$ level $\leq 7.0 \%$ at the end of the study.

\section{Discussion}

This study demonstrated the impact of an APh providing care to patients with type 2 diabetes under a CPA in a PCMH. The study found a significant reduction in HbA1c post APh intervention and it discerned the type of therapeutic decisions that the APh adopted during patient visits.

Previous studies also found positive effects of pharmacists' interventions in diabetes care outcomes. A meta-analysis of 14 clinical trials found that pharmacist interventions resulted in a $\mathrm{HbA} 1 \mathrm{c}$ reduction of $1.36 \% \pm 1.53 \%$ (95\% $\mathrm{Cl}: 0.83 \%-1.89 \%$ ) in type 1 and type 2 diabetes patients. ${ }^{25}$ Another meta-analysis including 22 studies found that pharmacists interventions in outpatient clinics resulted in a reduction of $0.85 \%$ in $\mathrm{HbA} 1 \mathrm{C}$ (95\% Cl: $0.65 \%-1.06 \%, \mathrm{p}<0.0001$ ) in type 2 diabetes patients. ${ }^{26}$
Furthermore, another study found a large $\mathrm{HbA1c}$ reduction in patients who enrolled in the pharmacist-management group compared to usual care. ${ }^{27}$

In our study, the APh made independent therapeutic decisions during patient visits. The primary care physicians at the clinic did not change any of the therapeutic decisions made by the APh. Several other studies have also shown that pharmacists working under a collaborative practice agreement are well accepted by physicians in group practice settings. ${ }^{28,29}$

While cost was not assessed in this study, previous studies demonstrated that pharmacists are cost-effective in managing diabetes in collaborative care programs. ${ }^{30} \mathrm{~A}$ previous study compared patients who achieved and did not achieve a decrease in $\mathrm{HbA1C}$ and found that patients with a decrease in $\mathrm{HbA1C}$ had $24 \%$ and $17 \%$ lower average annual healthcare costs during the first and second year of follow up, respectively. ${ }^{31}$

In addition to other outcome measures, Blue Shield, our ACO partner, has contracted measures on HbA1c reduction for patients. Thus, this pilot study was important to show that APh engagement can help improve performance metrics.

Our study found that the two most common therapeutic decisions made by the APh were drug dose increase and adding a new drug to the patient's regimen. Other therapeutic decisions included drug dose decrease, drug switch, and drug discontinuation. Those decisions may explain the reduction in HbA1c observed in this study.

The results of our study confirm the positive impact of the APh on diabetes care outcomes. The utilization of pharmacists to manage patients with complex chronic diseases not only improves patient outcomes, but it may also help to address the current shortage of primary care physicians. ${ }^{32}$

There were 10 patients who did not have a reduction in $\mathrm{HbA1c}$ values. These patients had varying levels of $\mathrm{HbA} 1 \mathrm{c}$ and we did not observe a pattern related to the number of visits, number of interventions, and type of interventions these patients had in relation to patients who exhibited a change in HbA1c. Although the pharmacist intervention did not result in the HgA1c reduction for 10 patients, it is important to note that these patients also did not see an increase in HbA1c. Future analysis should evaluate factors that explain why some patients do not experience a reduction in $\mathrm{HbA1c}$ levels.

There were 3 patients who received counseling and had their medications reviewed by the APh and who did not have any change in therapy. These patients also experienced a reduction in HbA1c. Future studies should assess the separate effects of APh's medication review and patient counseling on diabetes health outcomes. 
This study has some limitations. The study included a limited number of patients; however, differences in the primary outcome of the analysis were statistically significant with enough power to detect differences in the study outcome. An ongoing study with participation of additional clinical pharmacists is currently being conducted. While patients were asked and educated about adverse events such as hypoglycemia at each visit with the APh, we did not track these outcomes. Our study also did not track APh lifestyle modifications counseling interventions. Some patients may be able to lower their HbA1c values with diet and exercise alone and without medications or medication changes. The period of analysis was relatively short, but enough to demonstrate significant results and justify the expansion of the clinical pharmacist program.

\section{Conclusions}

An Advanced Practice Pharmacist led comprehensive type-2 diabetes management program under a collaborative practice agreement in a patient-centered medical home resulted in improvement in $\mathrm{HbA} 1 \mathrm{C}$ values. Changes in drug therapy, including drug dose increase and adding a new medication were the most common interventions made. APh pharmacists are a valuable part of the interprofessional health care team.

\section{Key Points}

- Advanced Practice Pharmacist is an integral part of an inter-professional team within a patient centered medical home.

- Independent therapeutic decision making by an Advanced Practice Pharmacist can improve HbA1c values.

- Pharmacist led chronic disease management is an important part of health care delivery within a health system.

\author{
List of Abbreviations \\ ACO - Accountable Care Organization \\ ADA - American Diabetes Association \\ APh - Advanced Practice Pharmacist \\ CDC - Centers for Disease Control \\ $\mathrm{Cl}-$ Confidence Interval \\ CPA - collaborative practice agreement \\ DSM - disease state management \\ HbA1c - Hemoglobin A1c \\ NP - Nurse Practitioner \\ PA- Physician Assistant \\ PCMH - patient centered medical home \\ PCP - Primary Care Physician \\ RN - Registered Nurse \\ SJMG - St. Jude Heritage Medical Group
}

\section{Declarations}

The authors do not have any conflicts of interest to disclose

Ethics approval and consent to participate

- $\quad$ Providence St. Joseph Heritage Healthcare and Chapman University IRB were obtained prior to study initiation.

Consent for publication

- Not applicable

Availability of data and material

- $\quad$ All data generated and analyzed during this study are included in this published article

Competing interests

- The authors declare that they have no competing interests

Funding

- No funding was provided throughout this study Authors' contributions

- $\quad$ All authors read and approved the final manuscript

- JL, TN, HA, MA, and ES collaborated on the conceptualization, study design, methodology design, data collection, data analysis, results interpretation, writing the manuscript, revising and providing comments to the manuscript

- $\quad$ BB, DK, and SC helped with conceptualization and study design as well as with revising and providing comments to the manuscript

Acknowledgements

- Not applicable

\section{References}

1. Centers for Disease Control and Prevention. National Diabetes Statistics Report, 2017. Atlanta, GA: Centers for Disease Control and Prevention, US Department of Health and Human Services; 2017.

2. Jabarpour Y, DeMarchis E, Bazemore A, Grundy P. The impact of primary care practice transformation on cost, quality, and utilization: A systematic review of research published in 2016. Patient-Centered Primary Care Collaborative; 2017.

https://www.pcpcc.org/sites/default/files/resources/pc mh_evidence_es_071417\%20FINAL.pdf. Published July 2017. Accessed March 1, 2019.

3. Coe $\mathrm{A}$, Choe H. Pharmacists supporting population health in patient-centered medical homes. Am J HealthSyst Pharm. 2017; 74:1461-6.

4. Scott MA, Heck JE, Wilson CG. The Integral Role of the Clinical Pharmacist Practitioner in Primary Care. N C Med J. 2017;78(3):181-5.

5. Albanese NP, Pignato AM, Monte SV. Provider Perception of Pharmacy Services in the PatientCentered Medical Home. J Pharm Pract. 2017;30(6):612-20. 
6. Stinger K, Curran V, Asghari S. Pharmacists and family physicians: improving interprofessional collaboration through joint understanding of our competencies. Front Pharmacol. 2013;4:151.

7. Pottie K, Farrell B, Haydt S. Integrating pharmacists into family practice teams: physicians' perspectives on collaborative care. Can Fam Physician. 2008;54(12):1714-7.

8. Hwang AY, Gums TH, Gums JG. The benefits of physician-pharmacist collaboration. J Fam Pract. 2017;66(12): E1-8.

9. Mouhtadi BB, Alame MM, Malaeb B, Hallit S, Salameh P, Malaeb D. Physician-community pharmacist collaborative care in diabetes management: a pilot study. J Drug Assess. 2018;7(1):61-5.

10. Chevalier B, Neville HL, Thompson K, Nodwell L, MacNeil M. Health Care Professionals' Opinions and Expectations of Clinical Pharmacy Services on a Surgical Ward. Can J Hosp Pharm. 2016;69(6):439-48.

11. Chisholm-Burns MA, Kim Lee J, Spivey CA, et al. US pharmacists' effect as team members on patient care: systematic review and meta-analyses. Med Care. 2010;48(10):923-33.

12. Dalton K, Byrne S. Role of the pharmacist in reducing healthcare costs: Current insights. Integr Pharm Res Pract. 2017;6:37-46.

13. Clifford RM, Davis WA, Batty KT, Davis TM, Fremantle Diabetes Study. Effect of a pharmaceutical care program on vascular risk factors in type 2 diabetes: The Fremantle Diabetes Study. Diabetes Care. 2005;28:7716.

14. Krass I, Armour CL, Mitchell B, et al. The Pharmacy Diabetes Care Program: Assessment of a community pharmacy diabetes service model in Australia. Diabetic Med. 2007;24:677-83.

15. Choe HM, Mitrovich S, Dubay D, et al. Proactive case management of high-risk patients with type 2 diabetes mellitus by a clinical pharmacist: a randomized controlled trial. Am J Manag Care. 2005;11:253-60.

16. Fornos JA, Andrés NF, Andrés JC, et al. A pharmacotherapy follow-up program in patients with type-2 diabetes in community pharmacies in Spain. Pharm World Sci. 2006;28:65-72.

17. Odegard PS, Goo A, Hummel J, et al. Caring for poorly controlled diabetes mellitus: a randomized pharmacist intervention. Ann Pharmacother. 2005;39:433-40.

18. Scott DM, Boyd ST, Stephan M, et al. Outcomes of pharmacist-managed diabetes care services in a community health center. Am J Health Syst Pharm. 2006;63:2116-22.

19. Al Mazroui NR, Kamal MM, Ghabash NM, et al. Influence of pharmaceutical care on health outcomes in patients with Type 2 diabetes mellitus. Br J Clin Pharmacol. 2009;67:547-57.
20. Jameson JP, Baty PJ. Pharmacist collaborative management of poorly controlled diabetes mellitus: a randomized controlled trial. Am J Manag Care. 2010;16:250-5.

21. Hawes EM, Lambert E., Reid A, Tong G, Gwynne M. Implementation and evaluation of a pharmacist-led electronic visit program for diabetes and anticoagulation care in a patient-centered medical home. Am J Health Sys Pharm. 2018;75(12): 901-10.

22.Ip EJ, Shah BM, Yu J, Chan J, Nguyen LT, Bhatt DC. Enhancing diabetes care by adding a pharmacist to the primary care team. Am J Health Syst Pharm. 2013;70(10):877-86.

23. Lamb KD, Baker JW, McFarland MS. Implementation of a pharmacotherapy clinic into the patient centered medical home model by a second year pharmacy resident. Am J Health Syst Pharm. 2015;72(17 Suppl 2):S83-9.

24. Matzke GR, Moczygemba LR, Williams KJ, Czar MJ, Lee WT. Impact of a pharmacist-physician collaborative care model on patient outcomes and health services utilization. Am J Health Syst Pharm. 2018;75(14):103947.

25. Collins C, Limone BL, Scholle JM, Coleman Cl. Effect of pharmacist intervention on glycemic control in diabetes. Diabetes Res Clin Pract. 2011;92(2):145-152.

26. Aguiar PM, Brito Gde C, Lima Tde M, Santos AP, Lyra DP $J r$, Storpirtis S. Investigating Sources of Heterogeneity in Randomized Controlled Trials of the Effects of Pharmacist Interventions on Glycemic Control in Type 2 Diabetic Patients: A Systematic Review and MetaAnalysis. PLoS One. 2016; 11(3):e0150999.

27. Pontefract B, King BS, King CA, Gothard DM. Impact of Pharmacist-Led Diabetes Management in Primary Care Clinics. INNOVATIONS in Pharmacy. 2018; 9(2): Article 17.

28. Campbell RK, Saulie BA. Providing pharmaceutical care in a physician office. J Am Pharm Assoc. 1998; 38:495-9.

29. Sardinha C. Physician groups embrace pharmacists: collaborations that work. J Manag Care Pharm. 1997; 3:526-30.

30. Franklin BE, Farland MZ, Thomas J, McFarland MS, Ray SM, Byrd DC. Pharmacoeconomic analysis of the diabetes initiative program: A pharmacist-physician collaborative care model. Ann Pharmacother. 2013;47(12):1627-34.

31. Bansal M, Shah M, Reilly B, Willman S, Gill M, Kaufman FR. Impact of Reducing Glycated Hemoglobin on Healthcare Costs Among a Population with Uncontrolled Diabetes. Appl Health Econ Health Policy. 2018;16(5):675-84.

32. Manolakis PG, Skelton JB. Pharmacists' contributions to primary care in the United States collaborating to address unmet patient care needs: the emerging role for pharmacists to address the shortage of primary care providers. Am J Pharm Educ. 2010;74(10):S7. 
Table 1. Patient Demographics

\begin{tabular}{lc}
\hline Parameters & Patients, $\mathbf{n}(\%)$ \\
\hline Age groups (years) & $1(2.9 \%)$ \\
$30-39$ & $3(8.6 \%)$ \\
$40-49$ & $6(17.1 \%)$ \\
$50-59$ & $13(37.1 \%)$ \\
$60-69$ & $11(31.4 \%)$ \\
$70-79$ & $1(2.9 \%)$ \\
$80+$ & $35(100.0)$ \\
Total & \\
\hline Sex & $16(45.7 \%)$ \\
Female & $19(54.3 \%)$ \\
Male & \\
\hline Race & $2(5.7 \%)$ \\
Asian & $1(2.9 \%)$ \\
Black or African & $1(2.9 \%)$ \\
Native Hawaiian & $1(2.9 \%)$ \\
Patient Declined & $4(11.4 \%)$ \\
Two or more Races & $26(74.3 \%)$ \\
White & \\
\hline Ethnicity & $16(45.7 \%)$ \\
Hispanic or Latino & $16(45.7 \%)$ \\
Non-Hispanic or Latino & \\
Patient Declines & $3(8.6 \%)$ \\
& \\
\hline BMI & $10(28.6 \%)$ \\
$25.0-29.9$ & $8(22.9 \%)$ \\
$30-35.9$ & $9(25.7 \%)$ \\
$36+$ & $8(22.9 \%)$ \\
Unknown & \\
\hline Pharmacist interventions $(\mathbf{n}) /$ & \\
Patient over multiple visits & $16(45.7 \%)$ \\
2 & $10(28.6 \%)$ \\
3 & $5(14.3 \%)$ \\
4 & $1(2.9 \%)$ \\
5 & $3(8.6 \%)$ \\
6 & \\
& \\
\hline & \\
\hline & \\
\hline & \\
\hline
\end{tabular}


Table 2. Clinical Pharmacist Therapeutic Interventions and Antidiabetic Drugs Involved

\begin{tabular}{lr}
\hline Parameters & Value, $\mathbf{n}(\%)$ \\
\hline Type of Interventions & \\
Dose increase & $39(35.5 \%)$ \\
Drug added & $18(16.4 \%)$ \\
Dose decrease & $7(6.4 \%)$ \\
Drug switch & $6(5.5 \%)$ \\
Drug discontinuation & $2(1.8 \%)$ \\
& \\
\hline Drugs & \\
metformin & $21(19.1 \%)$ \\
glimepiride & $13(11.8 \%)$ \\
insulin glargine & $12(10.9 \%)$ \\
glipizide & $6(5.5 \%)$ \\
insulin degludec & $1(0.9 \%)$ \\
exenatide & $1(0.9 \%)$ \\
glyburide & $1(0.9 \%)$ \\
sitagliptin & $1(0.9 \%)$
\end{tabular}

Table 3. Hemoglobin A1c levels Pre and Post intervention

\begin{tabular}{lrr}
\hline Parameters & $\begin{array}{c}\text { Pre intervention } \\
\mathbf{n}(\%)\end{array}$ & $\begin{array}{c}\text { Post intervention } \\
\mathbf{n}(\%)\end{array}$ \\
\hline HbA1c range & & $2(5.7 \%)$ \\
$<6 \%$ & 0 & $15(42.9 \%)$ \\
$6-6.9 \%$ & $3(8.6 \%)$ & $9(25.7 \%)$ \\
$7-7.9 \%$ & $6(17.1 \%)$ & $3(8.6 \%)$ \\
$8-8.9 \%$ & $10(28.6 \%)$ & $5(14.3 \%)$ \\
$9-9.9 \%$ & $11(31.4 \%)$ & $1(2.8 \%)$ \\
$>10 \%$, & $5(14.3 \%)$ & $\mathbf{3 5 ( 1 0 0 . 0 ) \%}$ \\
Total & $35(100.0) \%$ & $7.5 \% \pm 1.4 \%$ \\
Average* $\pm \mathrm{SD}$ & $8.8 \% \pm 1.4 \%$ & $5.5 \%-12.4 \%$ \\
Range & $6.0 \%-12.4 \%$ & $7.0 \%-8.0 \%$ \\
$95 \% \mathrm{Cl}$ & $8.3 \%-9.3 \%$ & \\
& & \\
\hline $\mathrm{HbA}_{1 \mathrm{c}}=$ glycosylated hemoglobin & \\
${ }^{\mathrm{p}}<0.0001$ &
\end{tabular}


Table 4. Pre and Post Intervention Hemoglobin A1c Levels, Visits and Therapeutic Interventions

\begin{tabular}{|c|c|c|c|c|c|c|}
\hline Patient & $\begin{array}{c}\text { Pre } \\
\text { HbA1c }\end{array}$ & $\begin{array}{l}\text { Post } \\
\text { HbA1c }\end{array}$ & $\begin{array}{c}\text { Pre-Post } \\
\text { HbA1c } \\
\text { Difference }\end{array}$ & $\begin{array}{l}\text { Number } \\
\text { of Visits }\end{array}$ & $\begin{array}{l}\text { Number of } \\
\text { Interventions }\end{array}$ & Type of Intervention (Number) \\
\hline 1 & $6.00 \%$ & $6.20 \%$ & $-0.20 \%$ & 3 & 1 & drug added (1) \\
\hline 2 & $6.60 \%$ & $6.60 \%$ & $0.00 \%$ & 4 & 1 & dose decrease (1) \\
\hline 3 & $6.80 \%$ & $6.80 \%$ & $0.00 \%$ & 4 & 1 & dose increased (1) \\
\hline 4 & $7.30 \%$ & $6.50 \%$ & $0.80 \%$ & 2 & 2 & $\begin{array}{l}\text { dose increased (1), drug discontinue } \\
\text { (1) }\end{array}$ \\
\hline 5 & $7.50 \%$ & $6.90 \%$ & $0.60 \%$ & 2 & 0 & none \\
\hline 6 & $7.70 \%$ & $7.60 \%$ & $0.10 \%$ & 2 & 1 & dose increased (1) \\
\hline 7 & $7.70 \%$ & $7.70 \%$ & $0.00 \%$ & 3 & 2 & dose increased (2) \\
\hline 8 & $7.80 \%$ & $7.80 \%$ & $0.00 \%$ & 5 & 4 & dose increased (2), dose decrease (2) \\
\hline 9 & $7.90 \%$ & $6.50 \%$ & $1.40 \%$ & 3 & 1 & drug added (1) \\
\hline 10 & $8.00 \%$ & $6.40 \%$ & $1.60 \%$ & 4 & 1 & drug added (1) \\
\hline 11 & $8.00 \%$ & $7.00 \%$ & $1.00 \%$ & 2 & 1 & drug added (1) \\
\hline 12 & $8.10 \%$ & $7.50 \%$ & $0.60 \%$ & 6 & 5 & dose increased (3), drug added (2) \\
\hline 13 & $8.10 \%$ & $8.10 \%$ & $0.00 \%$ & 2 & 1 & drug added (1) \\
\hline 14 & $8.20 \%$ & $8.20 \%$ & $0.00 \%$ & 2 & 0 & none \\
\hline 15 & $8.50 \%$ & $6.80 \%$ & $1.70 \%$ & 2 & 1 & drug added (1) \\
\hline 16 & $8.50 \%$ & $7.10 \%$ & $1.40 \%$ & 2 & 3 & dose increased (2), drug added (1) \\
\hline 17 & $8.60 \%$ & $5.90 \%$ & $2.70 \%$ & 6 & 3 & dose increased (2), drug switch (1) \\
\hline 18 & $8.80 \%$ & $6.70 \%$ & $2.10 \%$ & 5 & 4 & $\begin{array}{l}\text { dose increased (1), dose decrease (1), } \\
\text { drug switch (2) }\end{array}$ \\
\hline 19 & $8.80 \%$ & $5.50 \%$ & $3.30 \%$ & 2 & 1 & drug discontinue (1) \\
\hline 20 & $9.00 \%$ & $6.70 \%$ & $2.30 \%$ & 3 & 2 & dose increased (1), drug added (1) \\
\hline 21 & $9.20 \%$ & $6.80 \%$ & $2.40 \%$ & 2 & 1 & dose increased (1) \\
\hline 22 & $9.20 \%$ & $9.20 \%$ & $0.00 \%$ & 2 & 1 & drug added (1) \\
\hline 23 & $9.20 \%$ & $6.70 \%$ & $2.50 \%$ & 3 & 2 & dose increased (2) \\
\hline 24 & $9.40 \%$ & $7.90 \%$ & $1.50 \%$ & 3 & 4 & $\begin{array}{l}\text { dose increased (2), drug added (1), } \\
\text { dose decrease (1) }\end{array}$ \\
\hline 25 & $9.40 \%$ & $9.40 \%$ & $0.00 \%$ & 2 & 1 & dose increased (1) \\
\hline 26 & $9.40 \%$ & $7.90 \%$ & $1.50 \%$ & 3 & 2 & dose increased (2) \\
\hline 27 & $9.50 \%$ & $7.10 \%$ & $2.40 \%$ & 4 & 0 & none \\
\hline 28 & $9.60 \%$ & $6.00 \%$ & $3.60 \%$ & 2 & 2 & dose increased (1), dose decrease (1) \\
\hline 29 & $9.60 \%$ & $9.20 \%$ & $0.40 \%$ & 3 & 3 & dose increased (2), drug switch (1) \\
\hline 30 & $9.90 \%$ & $9.90 \%$ & $0.00 \%$ & 2 & 3 & dose increased (2), drug switch (1) \\
\hline 31 & $10.10 \%$ & $9.50 \%$ & $0.60 \%$ & 3 & 4 & dose increased (2), drug added (2) \\
\hline 32 & $10.20 \%$ & $8.30 \%$ & $1.90 \%$ & 4 & 3 & dose increased (1), drug added (2) \\
\hline 33 & $12.10 \%$ & $6.70 \%$ & $5.40 \%$ & 6 & 5 & $\begin{array}{l}\text { dose increased (1), drug added (2), } \\
\text { drug switch (1), dose decrease (1) }\end{array}$ \\
\hline 34 & $12.10 \%$ & $6.10 \%$ & $6.00 \%$ & 3 & 2 & dose increased (2) \\
\hline 35 & $12.40 \%$ & $12.40 \%$ & $0.00 \%$ & 4 & 4 & dose increased (4) \\
\hline
\end{tabular}

